\title{
Correspondence
}

Korean J Ophthalmol 2020:34(5):413-415 https://doi.org/10.3341/kjo.2020.0036

\section{Large-diameter Deep Anterior Lamel- lar Keratoplasty: An Alternative Treatment for Mooren Ulcer}

\section{Dear Editor,}

Mooren ulcer is an idiopathic autoimmune disease [1]. A broad variety of medical and surgical approaches for Mooren ulcer treatment have been developed, ranging from systemic immune suppression to conjunctival resection, lamellar keratoplasty, keratoepithelioplasty, deep anterior lamellar keratoplasty with amniotic membrane transplantation, tissue adhesives and tectonic graft [1-4].

We report a case of Mooren ulcer successfully treated with large-diameter deep anterior lamellar keratoplasty (DALK) after failure of other surgeries. A 40-year-old man presented to our ophthalmology department with pain and decreased visual acuity of the right eye. Upon examination, there was an epithelial defect and corneal thinning on the temporal side of his right eye (Fig. 1A). His corrected visual acuity was 0.6 in his right eye and 0.8 in his left eye (Snellen charts). Intraocular pressure was 12/17 mmHg. We suspected peripheral corneal ulcer reflecting Mooren ulcer or another collagen vascular disease in the right eye. Administered medical treatment included topical moxifloxacin twice a day, fuorometholone twice a day, and solcoseryl eye drops every 2 hours in the right eye.

Despite medical treatment, the corneal ulcer continued to progress and we performed a systemic work up to rule out corneal ulcer caused by collagen vascular disease. Systemic evaluation showed increased total cholesterol level ( $415 \mathrm{mg} / \mathrm{dL}$, reference120-220 mg/dL), low density lipo-

Received: March 19, 2020 Final revision: May 18, 2020

Accepted: May 25, 2020 protein cholesterol level $(210 \mathrm{mg} / \mathrm{dL}$, reference $<130 \mathrm{mg}$ / $\mathrm{dL})$ and fasting blood sugar $(600 \mathrm{mg} / \mathrm{dL}$, reference $<100$ $\mathrm{mg} / \mathrm{dL}$ ). No signs of rheumatologic diseases or infection were observed.

Based on these diagnostic tests, Mooren ulcer was suspected, and conjunctival resection and lamellar keratoplasty were performed in the right eye (Fig. 1B). After the first surgery, the graft was successful for 3 months, at which point the ulcer started to progress again both centrally and circumferentially despite strong immunosuppressive agents including topical and oral tacrolimus combined with steroid (Fig. 1C). To prevent ulcer progression, we performed keratoepithelioplasty (Fig. 1D), which failed to mitigate ulcer progression (Fig. 1E).

Six months after keratoepithelioplasty, we performed a second conjunctival resection and semi-annular lamellar keratoplasty (Fig. 1F). This graft was well maintained for 3 months with strong immune suppression. However, the graft then started to dissolve, and the remaining central island of the cornea began to melt again. The cornea showed extreme thinning near the point of perforation 4 months after semi-annular lamellar keratoplasty (Fig. 1G). His visual acuity had decreased to 0.02 .

Based on these values, additional surgical treatment was proposed, and we performed large-diameter deep anterior lamellar keratoplasty (Fig. 1H, 1I). Visual acuity slowly recovered and the large-diameter corneal graft remained clear with only topical immunosuppression for 9 consecutive months (Fig. 1J). Even with strong immunosuppression such as oral tacrolimus and steroid after surgical treatment, Mooren ulcer progresses and leads to corneal perforation in $11 \%$ to $13.3 \%$ of patients [1-3].

In intractable Mooren ulcer, there are several surgical treatment options [1-4]. Crescent or semi-annular lamellar keratoplasty can be enough when the ulcer progresses within that meridian. However, when the fulminant course of ulcerative changes continues in the centripetal and circumferential directions, the antigenic source of the cornea 

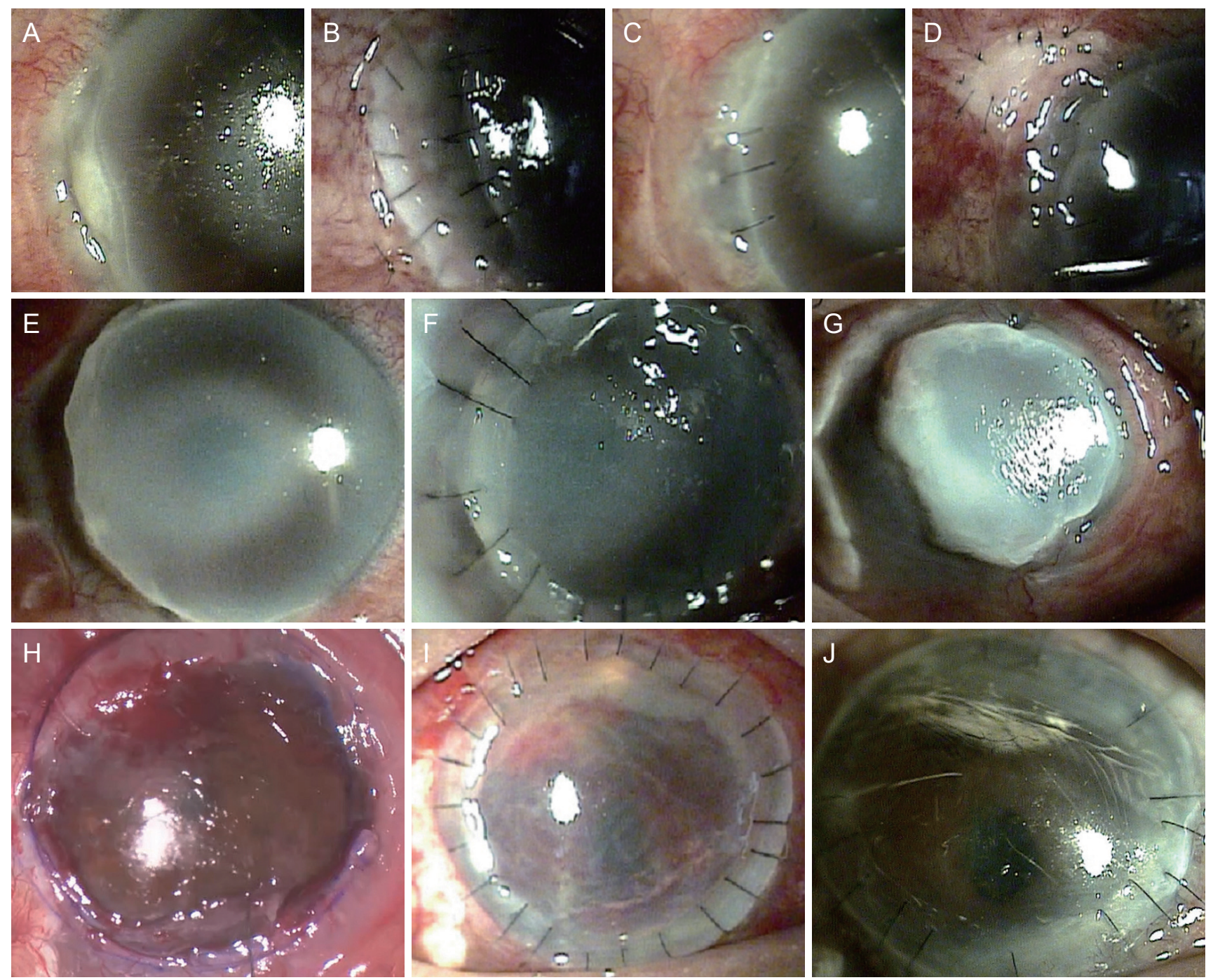

Fig. 1. Corneal change with time. (A) Corneal epithelial defect and thinning with overhanging edge at temporal side in right eye. (B) Crescentic lamella corneal graft at postoperative 1 day. (C) Melting crescentic lamella graft with inflammation. (D) In keratoepithelioplasty, corneal lenticule was sutured on bare sclera. (E) Melting total crescentic lamella graft and corneal lenticule with severe thinning progressing circumferentially and centrally. (F) Semi-annular lamella graft was re-sutured. (G) Melting semi-anuular graft with inflammation. $(\mathrm{H})$ Large $(9.5 \mathrm{~mm})$ diameter recipient bed was prepared after removing melted cornea in deep anterior lamella keratoplasty. (I) Large $(9.5 \mathrm{~mm})$ diameter anterior lamella graft was sutured. (J) Cornea remained clear without inflammation after large diameter deep anterior lamella keratoplasty. Informed consent for publication of the clinical image was obtained from the patients.

needs to be removed before further damage.

We found large-diameter DALK to be a useful alternative for treatment of Mooren ulcer. It can control the inflammatory process by removing the total cornea, except the endothelium and Descemet's membrane, which is the main antigenic stimulus in the pathogenesis of Mooren ulcer. The DALK procedure can be difficult when the cornea is perforated [5], so the decision to remove most of the corneal layer should be made before ulcerative changes lead to corneal perforation.
Yang Kyung Cho, Sun Young Lee, Ui Ju Cho St. Vincent's Hospital, The Catholic University of Korea, Suwon, Korea

E-mail (Yang Kyung Cho): yangkyeung@catholic.ac.kr

Balamurali K Ambati

Pacific Clear Vision Institute, Eugene, OR, USA 


\section{Conflict of Interest}

No potential conflict of interest relevant to this article was reported.

\section{References}

1. Lee HJ, Kim MK, Wee WR, Oh JY. Interplay of immune cells in Mooren ulcer. Cornea 2015;34:1164-7.

2. Krachmer JH, Mannis MJ, Holland EJ. Mooren ulcer. In: Krachmer JH, Mannis MJ, Holland EJ, editors. Cornea. 3rd ed. St. Louis: Mosby/Elsevier; 2011. p. 1149-53.

3. Guindolet D, Reynaud C, Clavel G, et al. Management of severe and refractory Mooren's ulcers with rituximab. $\mathrm{Br} J$ Ophthalmol 2017;101:418-22.

4. Wee SW, Choi SU, Kim JC. Deep anterior lamellar keratoplasty using irradiated acellular cornea with amniotic membrane transplantation for intractable ocular surface diseases. Korean J Ophthalmol 2015;29:79-85.

5. Huang OS, Htoon HM, Chan AM, et al. Incidence and outcomes of intraoperative descemet membrane perforations during deep anterior lamellar keratoplasty. Am J Ophthalmol 2019;199:9-18. 